\title{
Using Probabilistic Zone Model Simulations to Investigate the Deterministic Assumptions of UK Residential Corridor Smoke Control Design
}

Charlie Hopkin (1)*, Ashton Fire, This is the Space, 68 Quay Street, Manchester M3 $3 E J, U K$ and School of Mechanical, Aerospace and Civil Engineering, The University of Manchester, Manchester M13 9PL, UK Michael Spearpoint and Danny Hopkin, OFR Consultants, Sevendale House, Lever Street, Manchester M1 1JA, UK Yong Wang, School of Mechanical, Aerospace and Civil Engineering, The University of Manchester, Manchester M13 9PL, UK

Received: 2 October 2021/Accepted: 9 February 2022/Published online: 1 March 2022

\begin{abstract}
The modelling of common corridor smoke control systems in residential buildings is one of the most frequently undertaken performance-based assessments by fire engineers in the UK. However, there is limited understanding of how the deterministic assumptions provided in modelling guidance are derived, and to what extent these are representative of a range of possible outcomes. To place these assumptions into context, the Monte Carlo method is applied using the zone modelling software B-RISK for an exemplar residential arrangement. Distribution functions are adopted to inform inputs for fire parameters, sprinkler performance, and occupant behavioural characteristics. An output distribution for the corridor smoke clearance time is determined and compared to the clearance time of an equivalent set of deterministic simulations applying the assumptions of modelling guidance. The probabilistic study indicates that modelling guidance assumptions typically result in a scenario severity greater than the 99th percentile of possible outcomes. The work also considers the sensitivity of individual input parameters, ranking these based on their impact. These sensitivity analyses highlight the importance of occupant behavioural assumptions around the pre-evacuation time and door open time, and the significance of fire parameters including the elevation of the fuel bed, soot yield, and fire growth rate. Sprinkler parameters are shown to have a lesser impact on the corridor clearance time. The work therefore provides practitioners with an indication of which parameters are worth considering in greater detail when assessing scenario sensitivity.
\end{abstract}

Keywords: Residential, Smoke control, Common corridor, Fire and smoke modelling, Monte Carlo simulations

\footnotetext{
*Correspondence should be addressed to: Charlie Hopkin, E-mail: charlie.hopkin@ashtonfire.com
} 


\section{Background}

\subsection{Residential Corridor Smoke Control}

UK fire safety guidance documents, including Approved Document B (ADB) vol. 1 [1], BS 9991:2015 [2], and the Building Standards Technical Handbook: Domestic [3], recommend that the common corridor of multi-apartment residential buildings be afforded a means of smoke control. The performance objective for the smoke control in this situation is to protect the stair enclosure so that it "remain[s] relatively smoke-free" [2]. Guidance also suggests "the amount of smoke and other combustion products in the internal corridor or lobby [should be] kept to a minimum by providing either cross-corridor fire doors and ventilation, or a mechanical smoke ventilation system" [2]. However, as discussed by Hopkin et al. $[4,5]$, the natural smoke control systems recommended in guidance are shown to provide limited benefit to corridor smoke clearance and can result in prolonged periods for the corridor to clear after it has become contaminated with smoke. Hence, natural systems are usually only deemed sufficient when the corridor travel distances are restricted. Mechanical smoke control systems are therefore often adopted as an alternative when the corridor travel distances are greater than the maximum bounds recommended in guidance (a design feature commonly referred to as 'extended travel distances'). Under these circumstances, guidance in BS 9991:2015 [2] notes that the primary objective of the system is to "return the extended corridor and the associated stair enclosure to tenable conditions for means of escape and rescue purposes". This expectation usually results in a corridor smoke control system which incorporates both a means of exhaust and a means of inlet, to assist in smoke clearance. An indicative example of this type of system is presented in Fig. 1.

To determine whether a proposed corridor smoke control system can adequately support a design which includes extended travel distances, a performancebased, fire and smoke modelling assessment is usually undertaken [5]. This is one of the most frequently performed fire and smoke modelling assessments by fire safety practitioners in the UK. To undertake the assessment, typically the deterministic modelling methods of the Smoke Control Association (SCA) guidance on smoke control to common escape routes in apartment buildings (flats and maisonettes) [6] are followed, as referenced in BS 9991:2015 [2], although practitioners are free to adopt alternative guidance or utilise tailored performance based methods [5]. The SCA is an organisation which includes members comprising of smoke control system suppliers, and the organisation describes itself as "lead[ing] the way in promoting and enhancing the design, manufacture, installation and maintenance of life safety smoke ventilation systems..." [7]. It has previously been noted that SCA guidance is largely initiated by smoke control system suppliers with support from fire engineers, fire and rescue service personnel, and approvers, and it does not have standing equivalent to a guidance document published by the Government or through a standards-making organisation. However, its regularity of use within industry can cause stakeholders to place great importance on its contents [8]. 
In addition to guidance on residential smoke control, the SCA also provide guidance for computational fluid dynamics (CFD) analysis for smoke control design in buildings [9]. These documents are collectively referred to hereafter as 'SCA guidance'. It is important to note that much of the SCA guidance and its contents are not explicit and can be subject to differences in interpretation, and therefore the discussion contained within this paper are representative of the authors' understanding of the guidance.

\subsection{SCA Guidance}

The SCA guidance describes itself as a document which "covers information and requirements on the design, calculation methods, installation and testing of systems intended for smoke control within the common escape routes within apartment buildings" [6]. It suggests that where travel distances are extended, "a detailed engineering analysis is required on a deterministic basis" and suggests that this could range from 'hand calculations' to 'more sophisticated' tools such as zone or CFD modelling. As part of this recommended deterministic analysis, the guidance provides a methodology and recommended fire parameters, timelines, etc., for how to assess the performance of smoke control solutions to common corridors.

The SCA guidance considers the impact of the smoke control system on occupants during the means of escape phase, as well as the impact on firefighting operations later in the fire development timeline. For brevity, this paper focusses exclusively on the means of escape phase from this point onwards. As summarised by Hopkin et al. [5], a typical time-dependent modelling timeline for the means of escape phase considers: (1) the development of a fire within an apartment; (2) the

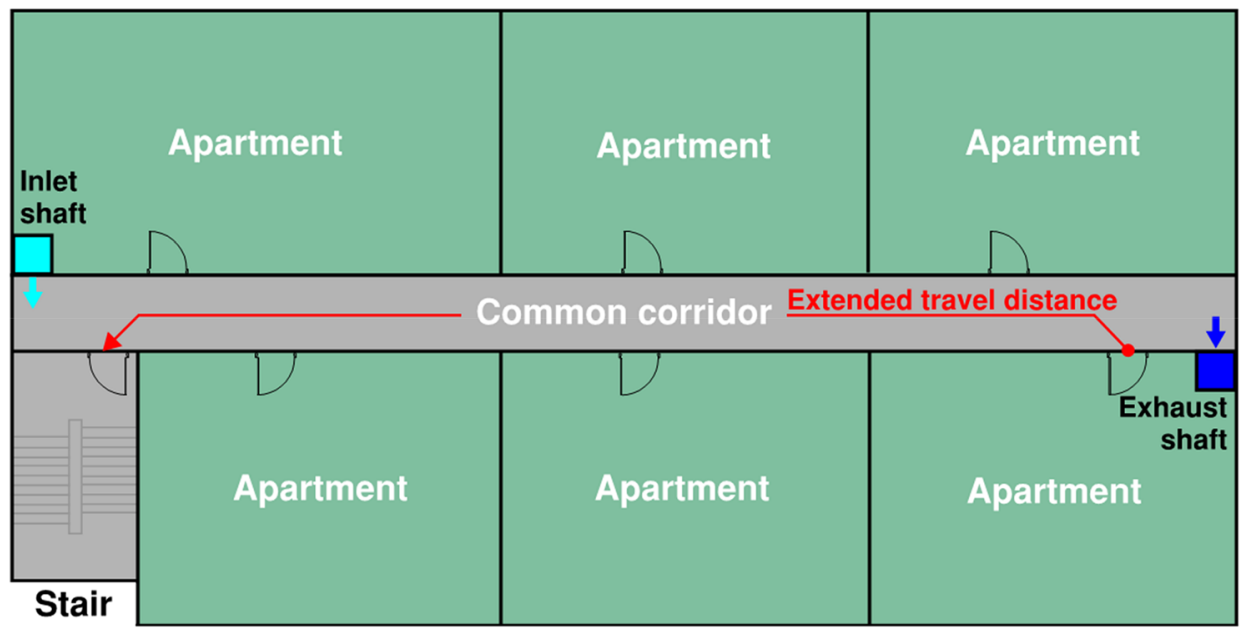

Figure 1. An example common corridor arrangement incorporating extended travel distances and a mechanical smoke control system. Adapted from Hopkin et al. [5]. 
occupants escaping from the fire-affected apartment, where the apartment door opens, smoke flows into the corridor and the door then closes behind them; and following this, (3) the corridor tenability is assessed and the smoke clearance time is determined. The SCA guidance suggests that a maximum time of 2 min, albeit with limited basis, for the corridor to return to tenable conditions (following the apartment door closing) should be achieved, where this time is determined relative to acceptance criteria for visibility, temperature, etc., discussed later. Thus, SCA guidance places no expectation that untenable conditions within the corridor be prevented, but instead that conditions are only untenable for up to a 2 min period.

\section{Research Purpose}

The deterministic assumptions of the SCA guidance are perhaps the most widely adopted in the UK when it comes to the assessment of the as-built performance of common corridor smoke control systems. These systems are a key fire safety feature, particularly in the design of single stair high-rise residential buildings. Given their significance and the potential consequences associated with failure, it is important to understand the achieved level of safety. However, there is uncertainty around how the recommended methods and parameters of the SCA guidance have been derived, as highlighted in the work of Hopkin et al. [5] on door open times. It is therefore beneficial to explore where these deterministic assumptions sit on a range of possible outcomes, and to broadly consider the extent that the collective assumptions are representative of events which could be observed in a real fire incident. To examine this topic, the paper details probabilistic simulations of a single exemplar residential common corridor arrangement using the zone modelling software B-RISK [10], where the Monte Carlo method has been applied. Probabilistic distribution functions (PDFs) from previous research have been adopted to inform the input parameters of the fire, including the growth rate (t-squared) [11], maximum HRR [11], soot yield [12-16], etc., as well as for the sprinkler performance in the apartment of fire origin (e.g., the reliability $[17,18]$ and thermal sensitivity [19]), and the behavioural characteristics of building occupants (the pre-evacuation time [20, 21] and the apartment door open time [5]). From the Monte Carlo zone modelling simulations, an output distribution for the smoke clearance time in the corridor is determined and then compared to the estimated clearance time of an equivalent set of simulations undertaken using the deterministic assumptions of SCA guidance. This serves to broadly observe the severity of incident which these assumptions represent on the range of outcomes. The paper also considers the sensitivity of the individual input parameters, and ranks these parameters based on their impact on the observed corridor clearance time.

In undertaking the assessment, the adopted exemplar (discussed in the next section) is considered to represent an as-built situation and applies common guidance assumptions that fire safety features of the building, such as fire doors and compartmentation, adequately perform their intended function. It is acknowledged 
that this does not necessarily capture the impact of potential failures in maintenance and any degradation of features resulting from building use. However, this topic would require careful investigation and is outside the scope of this paper.

\section{Exemplar Arrangement}

Mechanical common corridor smoke control with a corridor clearance capability is typically introduced in residential building situations where there are extended corridor travel distances, particularly in single stair buildings, where extended travel distances are more commonly observed. In England, extended travel in residential corridors (for single stair buildings) refers to situations where the distances from an apartment exit to a stair (or associated stair lobby) exceed either $7.5 \mathrm{~m}$ or $15 \mathrm{~m}$, depending on the adopted guidance document and the fire safety provisions in the building. Therefore, the simplified exemplar adopted in this study includes a common corridor which has a travel distance greater than $15 \mathrm{~m}$. In this instance, an $18 \mathrm{~m}$ long mechanically ventilated corridor has been considered, with an arrangement and provisions adapted from the exemplar of Hopkin et al. [4], where scenario uncertainty was previously considered in relation to mesh resolution in CFD modelling. The corridor has a width of $1.2 \mathrm{~m}$ and a floor to ceiling height of $2.4 \mathrm{~m}$, typical of apartment buildings across the UK. A diagram of the corridor arrangement and the associated apartment of fire origin is presented in Fig. 2.

The exemplar arrangement has a corridor which is ventilated with a mechanical exhaust at one end, achieving a volumetric flow rate of $3 \mathrm{~m}^{3} / \mathrm{s}$. Inlet is provided at the opposite end of the corridor by a natural ventilator to external air, with an

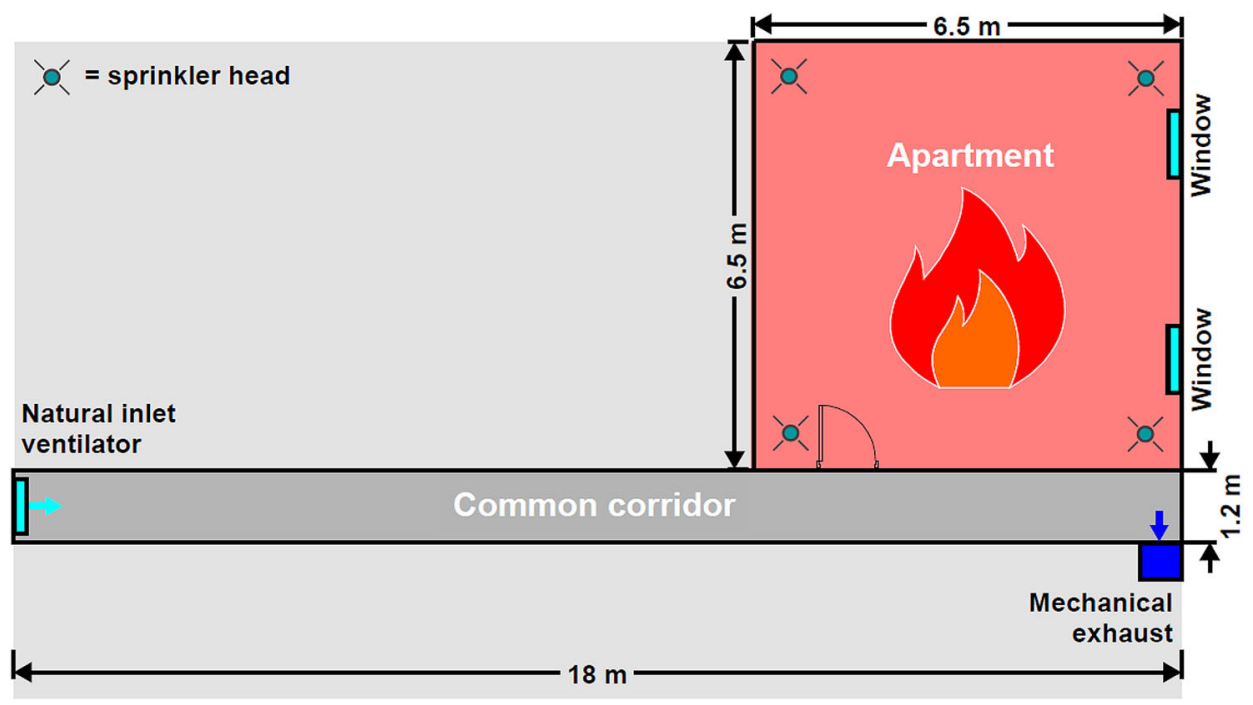

Figure 2. Simplified exemplar arrangement considered in this study. 
area of $0.8 \mathrm{~m}$ wide by $1.2 \mathrm{~m}$ high. Both provisions activate upon smoke detection within the corridor, and their arrangement and specification are representative of systems that could be found in modern residential buildings. The apartment of fire origin has been simulated as a one-bedroom apartment 'with restricted travel' (i.e., where internal travel distances do not exceed $9 \mathrm{~m}$ ) [22], otherwise referred to as a studio apartment, with dimensions of $6.5 \mathrm{~m}$ wide by $6.5 \mathrm{~m}$ long by $2.4 \mathrm{~m}$ high. This results in an apartment area of $42.25 \mathrm{~m}^{2}$, which approximately aligns with the average area of a one-bedroom apartment $\left(44.9 \mathrm{~m}^{2}\right)$ estimated by Hopkin et al. [23] from English Housing Survey (EHS) data.

An automatic fire detection and alarm system is represented in the apartment, in accordance with BS 5839-6:2019 [24]. The apartment is sprinkler protected with a BS 9251:2021 [25] system, incorporating concealed residential sprinkler heads tested to the thermal response room test detailed in BS EN 12259-14:2020 [26]. Four of these sprinkler heads are located in the apartment, spaced at $5.5 \mathrm{~m}$ from each other (the maximum spacing specified in BS 9251:2021), as indicated in Fig. 2. No sprinkler heads are located within the common corridor, as would be typical of buildings of this nature. The apartment and corridor are connected by a $0.8 \mathrm{~m}$ wide by $2 \mathrm{~m}$ high door. The apartment includes $4 \mathrm{~m}^{2}$ of glazing $(\sim 10 \%$ of the total floor area) in the form of two windows, each with dimensions of $2 \mathrm{~m}$ high by $1 \mathrm{~m}$ wide.

\section{Methodology}

\subsection{Modelling Tool, Validation, the Monte Carlo Method, and Acceptance Criteria}

The fire and smoke modelling of the exemplar arrangement has been undertaken using the B-RISK [10] fire zone modelling software, version 2021.2. B-RISK has been developed by BRANZ with support from the University of Canterbury. BRISK incorporates an underlying zone model which is used to calculate fire dynamics, smoke dispersion and temperature throughout enclosures, with each enclosure divided into two (upper and lower) gas layers. The fundamental equations are implemented as a system of differential equations which are solved to give outputs such as layer height, visibility, and layer temperature [19]. B-RISK also has the capability to run multiple iterations of simulations based on probabilistic inputs. The relative simplicity of a zone model means that B-RISK can run simulations in a short timeframe, with the capability to run thousands of simulations without any substantial reliance on computing power [19].

The enclosure dimensions and simulated heat release rates (HRRs, discussed later) for the study are within the suggested bounds of BRANZ report TR17 [27], suggesting that zone modelling is an appropriate assessment tool for the given fire and enclosure sizes [28]. The B-RISK study report SR292 [29] includes examples of benchmarking cases for multi-room scenarios incorporating corridors, indicating reasonable agreement between experimental data and B-RISK estimations. Similarly, Harrison et al. [30] demonstrate B-RISK's capability to adequately estimate the layer height for spill plumes spreading into both naturally and mechani- 
cally ventilated spaces. B-RISK includes well-validated sub-models for estimating the time of sprinkler activation, including the NIST/JET ceiling jet model [31]. Work by both Wade et al. [32] and Hopkin and Spearpoint [33] demonstrate that B-RISK provides a reasonable estimation of sprinkler activation times in simple rectilinear enclosures.

For the probabilistic modelling, the Monte Carlo method has been applied. The Monte Carlo method uses pseudo-random number generators and repeated sampling of input distribution functions to generate an output sample distribution, where this distribution is intended to provide a reasonable estimation of the range of possible outcomes under study [34]. B-RISK adopts a stratified sampling method [10] for Monte Carlo simulations (MCS), where the distribution is stratified into different regions and samples are taken from each region so that values are more efficiently selected across the distribution [35].

The modelling of the exemplar arrangement focusses on the time it takes for a corridor to 'clear' once it becomes compromised with smoke following initial occupant escape, using probabilistic modelling to generate a range of possible corridor 'clearance' times. The resultant output distribution for the corridor clearance time is then compared to a single deterministic simulation applying the modelling recommendations of the SCA guidance. In this instance, the corridor clearance time (i.e., the time for the corridor to return to tenable conditions) has been estimated as a function of typical acceptance criteria outlined in SCA guidance and PD 7974-6:2019 [36]. Namely, the corridor is considered tenable when visibility returns to $10 \mathrm{~m}$ or greater and temperatures are below $60^{\circ} \mathrm{C}$, both at a height of $2 \mathrm{~m}$ from floor level.

By default, B-RISK has the capability to include four different distribution types of normal, lognormal, triangular, and uniform (as well as discrete probabilities for parameters such as sprinkler reliability). Therefore, all distribution functions have been adapted from referenced literature to best align with one of these four distribution types. These distributions and discrete probabilities are detailed in the following sections, along with comparisons to SCA guidance recommendations.

\subsection{Fire Properties}

The distribution functions and SCA guidance recommendations for the fire properties are summarised and presented in Table 1. In some instances, the distribution functions are taken directly from the referenced literature, such as for the fire growth rate, maximum HRR, heat release rate per unit area (HRRPUA), and the elevation of the fuel bed. Albeit the last of those is described by Hopkin et al. [28] as being "arbitrarily selected (with no known literature available to the authors)". Other distribution functions have been estimated from previous experimental studies and data. These include: the effective heat of combustion, where a truncated normal distribution has been estimated from 13 experiments of upholstered furniture fires by Babrauskas et al. [37]; and the radiative fraction, which uses a uniform distribution for a range of cellulosic and non-cellulosic fuel types detailed in PD 7974-1:2019 [38]. 
Table 1

Fire Properties for Probabilistic Modelling Compared to SCA Guidance Assumptions

\begin{tabular}{|c|c|c|c|c|}
\hline Parameter & Distribution function & Refs & $\begin{array}{l}\text { SCA guidance determin- } \\
\text { istic assumption or rec- } \\
\text { ommendation }^{\mathrm{a}}\end{array}$ & $\begin{array}{l}\text { Percentile of SCA value } \\
\text { relative to distribution } \\
\text { function }[\%]\end{array}$ \\
\hline $\begin{array}{l}\text { Fire growth } \\
\text { rate }(\alpha) \\
{\left[\mathrm{kW} / \mathrm{s}^{2}\right]}\end{array}$ & $\begin{array}{l}\text { Lognormal } \\
\text { mean }=0.0062, \text { std } \\
\qquad \operatorname{dev}=0.0140\end{array}$ & {$[11]$} & 0.0117 [Medium] & 88 \\
\hline $\begin{array}{l}\text { Soot yield } \\
{[\mathrm{kg} / \mathrm{kg}]}\end{array}$ & $\begin{array}{l}\text { Lognormal } \\
\text { mean }=0.034, \text { std } \\
\quad \operatorname{dev}=0.036\end{array}$ & $\begin{array}{l}{[12-} \\
16]\end{array}$ & 0.100 & 95 \\
\hline $\begin{array}{l}\text { HRRPUA } \\
{\left[\mathrm{kW} / \mathrm{m}^{2}\right]}\end{array}$ & $\begin{array}{l}\text { Uniform } \\
\min =320 \\
\quad \max =570\end{array}$ & [39] & $320^{\mathrm{b}}$ & 0 \\
\hline $\begin{array}{l}\text { Maximum } \\
\operatorname{HRR}^{\mathrm{c}}[\mathrm{kW}]\end{array}$ & $\begin{array}{l}\text { Lognormal } \\
\text { mean }=1600, \text { std } \\
\quad \text { dev }=3000^{c}\end{array}$ & {$[11]$} & 1000 and $635^{\mathrm{d}}$ & 60 and 45 \\
\hline $\begin{array}{l}\text { Effective heat } \\
\text { of combus- } \\
\text { tion }[\mathrm{MJ} / \mathrm{kg}]\end{array}$ & $\begin{array}{l}\text { Truncated normal } \\
\text { mean }=18.3, \text { std } \\
\quad \operatorname{dev}=5.4, \min = \\
11.9, \max =35.1\end{array}$ & {$[37]$} & 20.0 & 68 \\
\hline $\begin{array}{l}\text { Radiative frac- } \\
\text { tion }[-]\end{array}$ & $\begin{array}{l}\text { Uniform } \\
\min =0.31 \\
\max =0.59\end{array}$ & {$[38]$} & $0.35^{\mathrm{e}}$ & 14 \\
\hline $\begin{array}{l}\text { Elevation of } \\
\text { fuel bed [m] }\end{array}$ & $\begin{array}{c}\text { Truncated normal } \\
\text { mean }=0.5, \text { std } \\
\begin{array}{c}\operatorname{dev}=0.6 \\
\min =0.0 \\
\max =2.2\end{array}\end{array}$ & {$[28]$} & $0.0^{\mathrm{f}}$ & 0 \\
\hline
\end{tabular}

${ }^{a}$ This includes both SCA guidance on smoke control to common escape routes in apartment buildings (flats and maisonettes) [6] and SCA guidance for computational fluid dynamics (CFD) analysis for smoke control design in buildings [9]. Where neither document provides an explicit recommendation, previous revisions of SCA guidance have been considered $[40,41]$

${ }^{\mathrm{b}}$ SCA guidance does not provide a recommendation for HRRPUA, and therefore the lowest value from PD 79741:2019 [38] for residential buildings has been used. A lower HRRPUA for a given HRR would result in a greater fire area and thus a greater estimation of perimeter entrainment [42]

${ }^{\mathrm{c}}$ The initial input distribution for the maximum HRR is specified assuming an absence of sprinkler involvement, with the performance of sprinklers being dependent on the discrete probabilities (i.e., likelihood of operation and extinguishment), which are discussed later

${ }^{\mathrm{d}}$ The modelling for the SCA guidance case considers both a $1 \mathrm{MW}$ and $635 \mathrm{~kW}$ maximum HRR. The former has been selected based on the statement that a $1 \mathrm{MW}$ HRR "might be considered appropriate at the time the occupants of the fire apartment make their escape". The latter has been selected for a fire controlled by sprinklers. Further discussions on this, as well as assumptions related to sprinkler performance, are included later

${ }^{\mathrm{e}} \mathrm{SCA}$ guidance does not provide a recommendation for the radiative fraction. A value of 0.35 has been used, which aligns with the default Fire Dynamics Simulator (FDS) [43] value for 'all other species'. It is also the recommended pre-flashover design fire value from C/VM2 [44] for general building contents and is considered representative of standard industry practice from the anecdotal observations of the authors

${ }^{\mathrm{f}} \mathrm{SCA}$ guidance does not provide a recommendation for the elevation of the fuel bed. A minimum value of $0.0 \mathrm{~m}$ has been used (i.e., a fire at floor level), considered representative of standard industry practice from the anecdotal observations of the authors 
The adopted soot yield distribution function expands on previous work by Robbins and Wade [12] for soot yields of residential occupancies. Robbins and Wade referred to the 'combustion behaviour of upholstered furniture' (CBUF) research programme [13], which included soot yield data for 27 different furniture fire experiments. From this, a soot yield design value of $0.07 \mathrm{~kg} / \mathrm{kg}$ was proposed, equivalent to a 95th percentile of the CBUF data. However, to determine this value, Robbins and Wade excluded a single 'high' yield outlier. It is proposed in this paper that the outlier should be included to represent the full range of data. The dataset has also been expanded to include experimental data for 14 furniture fires from Babrauskas and Krasny [14], 14 furniture fires from Gann et al. [15], and soot yield estimations from 11 residential room fires detailed by Fang and Breese [16]. This has resulted in 66 datapoints in total, and these are considered to be broadly representative of the types of fuels observed in apartments. The majority of the collated experimental data is representative of free-burn or room experiments in which conditions were considered well-ventilated. The exception to this is the experiments of Fang and Breese [16], where it is reported fires were frequently controlled at different stages as a result of ventilation available to the enclosure.

The adopted PDF for the soot yield is presented in Fig. 3, equated to a lognormal distribution with a mean of $0.034 \mathrm{~kg} / \mathrm{kg}$ and a standard deviation of $0.036 \mathrm{~kg} /$ $\mathrm{kg}$. The 95th percentile in this amended distribution is $0.1 \mathrm{~kg} / \mathrm{kg}$. For clarity of presentation, the $\mathrm{x}$-axis of Fig. 3 is capped at $0.205 \mathrm{~kg} / \mathrm{kg}$ due to low probabilities observed in the distribution function beyond this point. However, data points used to estimate the distribution function exist beyond this range, such as the $0.37 \mathrm{~kg} / \mathrm{kg}$ outlier previously excluded by Robbins and Wade.

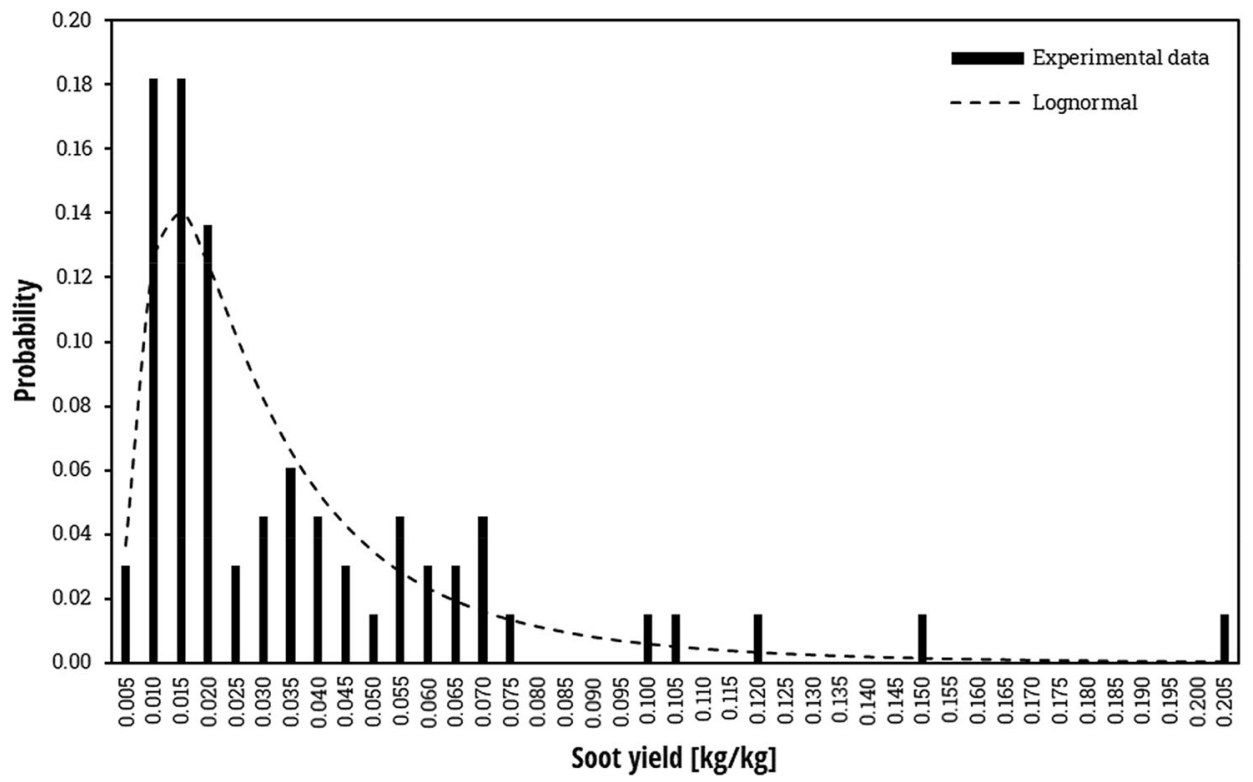

Figure 3. PDF for soot yield presented with $0.005 \mathrm{~kg} / \mathrm{kg}$ bins. 
The soot yield distribution function has been specified in B-RISK as a pre-flashover yield as part of the fire item specification. In the rare event that flashover is estimated to occur, then a default value of $0.14 \mathrm{~kg} / \mathrm{kg}$ is applied. Should ventilation-controlled conditions be estimated, then the impact this may have on the soot yield has not been captured in the modelling.

\subsection{Sprinkler Properties}

The distribution functions for the probabilistic sprinkler properties are presented in Table 2. Uniform distributions have been used for the response time index (RTI) and conductivity factor (C factor). These distributions have been estimated from the work of Hopkin and Spearpoint [19], who used probabilistic modelling to estimate the relationship needed between RTI and C factor to pass the BS 9252:2011 [45]/BS EN 12259-14:2020 [26] thermal response room test for concealed residential sprinkler heads. This was then compared to previous experimental data for concealed sprinkler heads from Annable [46] and $\mathrm{Yu}$ [47]. Figure 4 provides an indication of the relationship estimated by Hopkin and Spearpoint in relation to the experimental data, with the highlighted region representing the adopted uniform distributions for the RTI and C factor. The dashed line indicates the relationship needed to pass the thermal response room test for concealed sprinkler heads, as estimated by Hopkin and Spearpoint [19], while the solid black line indicates the RTI and C factor values needed to pass the plunge and ramp tests (described in BS EN 12259-14:2020) typically used for exposed pendent heads.

The radial distance $(r, \mathrm{~m})$ between the centreline of the fire plume and the sprinkler head has been determined using the principles given by Fraser-Mitchell and Williams [48], by applying the Pythagorean theorem:

$$
r=\sqrt{x^{2}+y^{2}}
$$

where $x(\mathrm{~m})$ and $y(\mathrm{~m})$ are the distance of the flame centreline to the sprinkler head in the $\mathrm{x}$ and $\mathrm{y}$ directions, assuming randomly distributed values between a lower bound of $0 \mathrm{~m}$ and an upper bound of $2.75 \mathrm{~m}$, for an equidistant maximum sprinkler spacing of $5.5 \mathrm{~m}$, as per BS 9251:2021 [49]. This relationship has been

\section{Table 2}

Sprinkler Properties for Probabilistic Modelling

\begin{tabular}{lll}
\hline Parameter & \multicolumn{1}{c}{ Distribution function } & References \\
\hline RTI $\left[\mathrm{m}^{1 / 2} \mathrm{~s}^{1 / 2}\right]$ & Uniform $\min =50, \max =300$ & {$[19]$} \\
$\mathrm{C}$ factor $\left[\mathrm{m}^{1 / 2} \mathrm{~s}^{-1 / 2}\right]$ & Uniform min $=0.4, \max =1.0$ & {$[19]$} \\
Radial distance $[\mathrm{m}]$ & Triangular $\min =0.00, \max =3.89$, mode $=2.65$ & {$[-]$} \\
Control likelihood $[-]$ & Discrete $p=0.89$ & {$[17]$} \\
Suppression likelihood $[-]$ & Discrete $p=0.69$ & {$[18]$} \\
\hline
\end{tabular}




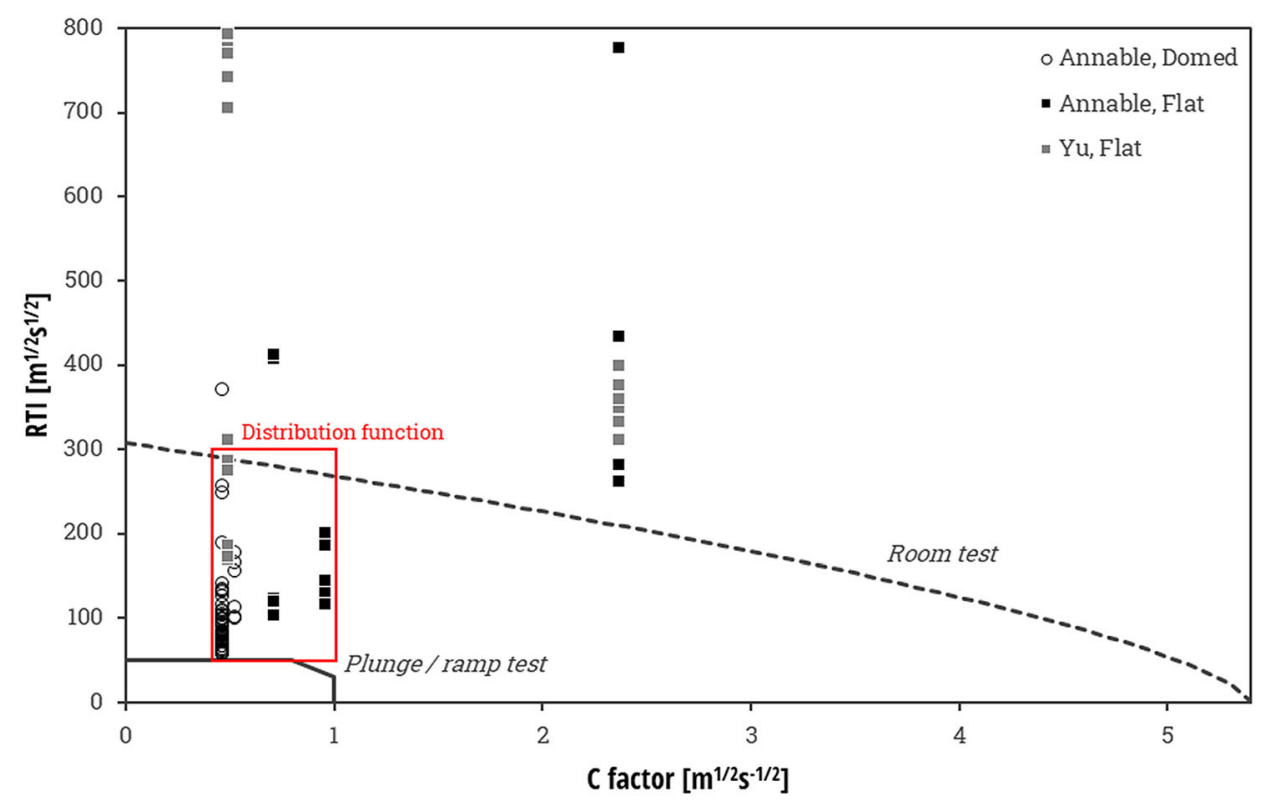

Figure 4. Performance of concealed sprinkler heads in relation to
test methods. Adapted from Hopkin and Spearpoint [19].

approximated to a triangular distribution, with a minimum of $0 \mathrm{~m}$, a mode of $2.65 \mathrm{~m}$ and a maximum of $3.9 \mathrm{~m}$.

Where sprinklers successfully actuate but 'fire suppression' does not occur, BRISK adopts a method where, upon actuation, the fire is capped at a constant HRR (i.e., it is 'controlled'). When applying a value for suppression reliability, BRISK can also simulate the impact of suppression on HRR using an algorithm developed by Evans [19] for unshielded furniture fires. Both methods have been represented in the modelling depending upon the discrete probabilities for sprinkler reliability and suppression. For reliability, PD 7974-7:2019 [17] refers to US sprinkler reliability data where, for residential occupancies, $89 \%$ of relevant incidents resulted in sprinklers 'operating effectively'. With respect to the likelihood of suppression, Ikehata et al. [18] determined that, for office and shop fire reports collated in Japan, the probability that a fire is successfully extinguished by sprinklers is $69 \%$. While this data is not directly applicable to residential buildings, estimates of operation reliability by Bukowski et al. [50] indicate that there is limited information on the reliability of modern-day residential sprinkler systems. In the absence of available data, the Ikehata et al. suppression probability has been adopted in this paper.

In addition to the distribution functions and discrete probabilities, fixed values have been used for several other sprinkler parameters. A water spray density of $4 \mathrm{~mm} / \mathrm{min}$ has been adopted, using the single head operation minimum discharge density for a Category 4 residential sprinkler system, as specified in BS 9251:2021 [49]. A sprinkler offset of $50 \mathrm{~mm}$ (relative to the ceiling) has been adopted, based 
on previous model calibration studies carried out by Hopkin and Spearpoint [19] for concealed residential sprinkler heads.

The bulb of each sprinkler head is assumed to achieve a rated temperature of $68^{\circ} \mathrm{C}$, equivalent to a red bulb specified in BS EN 12259-14:2020 [26]. For simplicity, an indoor ambient temperature of $20^{\circ} \mathrm{C}$ and an outdoor temperature of $15^{\circ} \mathrm{C}$ have been adopted for all simulations, although in practice indoor and outdoor temperatures may change depending on building use and seasonal variations.

SCA guidance suggests that a 1 MW HRR "might be considered appropriate at the time the occupants of the fire apartment make their escape" but goes on to say, "Where water suppression is to be considered, it might be appropriate to assume that the fire grows until the suppression activates and then remains fixed at this size". With respect to sprinkler activation time, the B-RISK zone model estimates that the sprinklers would activate at $233 \mathrm{~s}$ with a maximum HRR of $635 \mathrm{~kW}$ when assuming a medium fire growth rate and using the Hopkin and Spearpoint [19] recommended deterministic thermal sensitivity parameters for concealed residential sprinkler heads (i.e., RTI $=290 \mathrm{~m}^{1 / 2} \mathrm{~s}^{1 / 2}, \quad \mathrm{C}$ factor $=0.5 \mathrm{~m}^{1 / 2} \mathrm{~s}^{-1 / 2}$, with a maximum radial distance to a sprinkler head of $3.89 \mathrm{~m}$. The deterministic modelling has therefore been undertaken for two maximum HRR values, i.e., in two separate simulations. The first uses a $1 \mathrm{MW}$ maximum HRR which excludes the potential for sprinkler involvement during the means of escape phase, and the second uses a $625 \mathrm{~kW}$ maximum HRR which has been estimated from the sprinkler activation time.

\subsection{Geometric and Surface Properties}

Table 3 provides the surface properties adopted for the modelling geometry. All wall, ceiling and object construction has been modelled as $15 \mathrm{~mm}$ thick gypsum plasterboard surfaces based on properties defined by Hopkin et al. [51] and slabs have been simulated with concrete properties estimated from BS EN 1992-12:2004 [52]. The SCA guidance does not make explicit recommendations on what surface properties should be considered for the modelling and, therefore, properties consistent with Table 3 have been adopted for this study.

\section{Table 3}

Surface properties adopted for the room and corridor enclosures, based on BS EN 1992-1-2:2004 [52] Hopkin et al. [5 1 ]

\begin{tabular}{lll}
\hline Parameter & Concrete & Gypsum plasterboard \\
\hline Surface $[-]$ & Slabs & Walls and ceilings \\
Thickness $[\mathrm{mm}]$ & 100 & 15 \\
Density $\left[\mathrm{kg} / \mathrm{m}^{3}\right]$ & 2300 & 780 \\
Specific heat $[\mathrm{kJ} / \mathrm{kg} / \mathrm{K}]$ & 0.90 & 0.95 \\
Thermal conductivity $[\mathrm{W} / \mathrm{m} / \mathrm{K}]$ & 1.40 & 0.25 \\
Emissivity $[-]$ & 0.7 & 0.7 \\
\hline
\end{tabular}


The B-RISK software provides an idealised representation of air flow within the domain, i.e., it considers that the enclosure is perfectly sealed aside from any user specified openings. In practice, the enclosures will incorporate natural air flow resulting from factors such as leakages through wall and ceiling construction, around window gaps (and through any open windows), through door gaps, etc. Therefore, to represent this, an opening has been included within the probabilistic simulations to support the onset of combustion prior to any fire-induced glazing failure. This initial opening is positioned at low-level, with dimensions of $2 \mathrm{~m}$ wide by $1 \mathrm{~m}$ high $\left(2 \mathrm{~m}^{2}\right)$, to allow for enough oxygen to reach the fuel bed to sustain the HRR development while minimising the estimated smoke and heat losses from the apartment. These vent dimensions represent approximately $1 / 20$ th of the room of fire origin floor area, which is consistent with the recommendations of Approved Document F [53] for purge vent to apartments, e.g., the free area available from openable windows or external balcony doors. This broadly aligns with the recommendations of the SCA guidance [9], which indicatively suggests a $1.25 \mathrm{~m}$ by $1.25 \mathrm{~m}\left(\sim 1.6 \mathrm{~m}^{2}\right)$ low-level vent for a $1 \mathrm{MW}$ HRR, and a $1.5 \mathrm{~m}$ by $1.5 \mathrm{~m}$ vent $\left(\sim 2.3 \mathrm{~m}^{2}\right)$ for a $2.5 \mathrm{MW} \mathrm{HRR}$.

The potential for windows in the apartment to break has been integrated into the probabilistic simulations using the glass fracture model available within BRISK, which is based on the work of Parry et al. [54].

The SCA guidance [9] provides what might be considered conflicting advice on whether window breakage in apartments should be captured in common corridor modelling assessments. One the one hand, it suggests that an "artificial vent" should be "conservatively set as low as possible without having a significant impact of the airflow dynamics" and that "high level vents are not desirable for assessment", although it is not clear whether this latter statement is referring to window openings. Elsewhere it suggests "Using artificial opening [sic] requires careful consideration. Actual window openings provide more accurate assessment" and "The low-level vent is not physically realistic but can give an upper bound on the smoke control systems [sic] air flow rates needed." Given the lack of clarity, this study adopts the more 'conservative' assumption, where the potential for window failure has been excluded in the deterministic simulation corresponding to the SCA guidance, and only a low-level opening is incorporated. For the probabilistic simulations, the potential for fire-induced glazing failure has been captured, as noted above.

\subsection{Behavioural Properties, Evacuation Timeline, and Smoke Control System Activation}

A traditional means of escape modelling timeline detailed in the SCA guidance assumes that, at a given time during fire development, occupants collectively escape from the fire-affected apartment. In this process, the apartment door opens, smoke from the apartment flows into the corridor, and then the door closes behind the occupants. After this occurs, the smoke control system in the corridor activates, the corridor tenability is assessed, and the smoke clearance time is determined (measured from the period that the apartment door closes). As this 
assessment focusses exclusively on the corridor clearance time in the initial means of escape phase, consideration of both the use of the stair and firefighting operations have been excluded. A representation of the timeline is provided in Fig. 5, along with the distribution functions adopted in the probabilistic modelling.

It may be reasonably hypothesised that the initial time for the door to open from the apartment into the corridor is largely linked to the occupants' pre-evacuation time, although it will also be influenced by the conditions within the apartment itself. For the purposes of this study, the pre-evacuation process has been heavily simplified, where it is assumed that all physical movement and information or action tasks, such as occupant seeking, providing or exchanging information concerning the fire, investigating the incident, etc. [55], are collectively undertaken within the apartment. It is also assumed that occupants successfully make their escape irrespective of the conditions observed within the apartment, and that the process of making their escape is not affected by these conditions. In addition, the detection and alarm time is not considered, although this will be small relative to the pre-evacuation time. As a result, the time that the apartment door opens is directly equated to the pre-evacuation time. There are a number of different preevacuation time distributions which could be considered, many of which are detailed by Lovreglio et al. [20, 21], Gwynne and Boyce [56], as well as the distribution functions recommended in PD 7974-6:2019 [36]. In this instance, as the apartment is a studio arrangement, occupants would be expected to be in the room of fire origin and would have an increased awareness of the fire compared to a situation where occupants are remote from a fire. The apartment is also provided with an automatic detection and alarm system. Therefore, a distribution function has been adopted for the recommended 'cluster 1' parameters detailed by Lovreglio et al. [20, 21] (i.e., the cluster of cases where 'poor alarm performance' was not observed), using a lognormal distribution with a mean of $165 \mathrm{~s}$ (2.8 min)

$\mathbf{t}_{0}$

$\mathbf{t}_{1}$

$t_{2}$

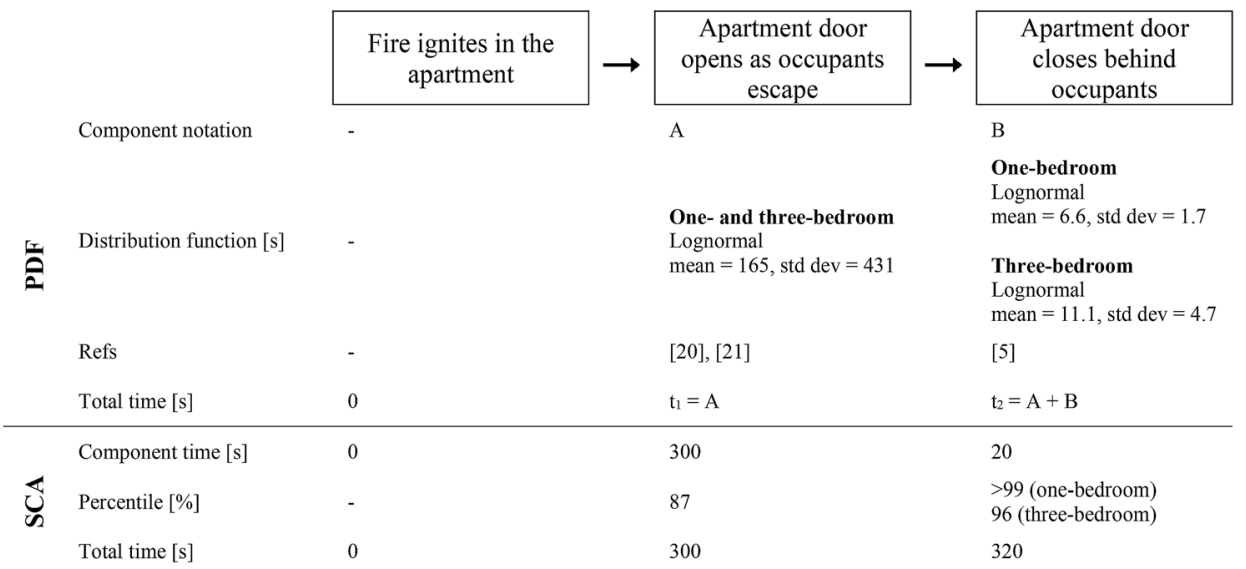

Figure 5. Evacuation timeline and behavioural properties for probabilistic modelling compared to SCA guidance assumptions. 
and a standard deviation of $431 \mathrm{~s}$ (7.2 min). This dataset represents a combined seven case studies across the US, Canada, and the UK, including data for university residences and residential care homes. The resultant distribution function therefore encapsulates a wide range of potential pre-evacuation times, with the 99th percentile resulting in a pre-evacuation time of nearly $28 \mathrm{~min}$. In comparison, SCA guidance [9] suggests "If a medium growing t-squared fire is assumed, then after $5 \mathrm{~min}$ the heat release rate will be approximately $1 \mathrm{MW}$. This size of fire might be considered as appropriate at the time the occupants of the fire apartment make their escape." This $5 \mathrm{~min}(300 \mathrm{~s})$ time is equivalent to the 87 th percentile of the pre-evacuation distribution function.

The time for the door to remain open during occupant escape has been estimated previously by Hopkin et al. [5]. A simple calculation method was considered, using probabilistic input functions from previous data recorded by Frank [57] and Hopkin et al. [23], to estimate an output distribution of potential door open times for occupants escaping from apartments. For a one-bedroom apartment, it was proposed that the door open time could be represented using a lognormal distribution with a mean of $6.6 \mathrm{~s}$ and a standard deviation of $1.7 \mathrm{~s}$. In comparison, SCA guidance recommends a door open time of $20 \mathrm{~s}$. Hopkin et al. [5] noted that this represented the 96th up to greater than the 99th percentile, depending on the number of beds / bedrooms in the apartment. Hopkin et al. also demonstrated the importance of this parameter on the estimated quantity of smoke entering the corridor. Therefore, to assess the sensitivity of the door open time, simulations have also been run using a door open time distribution for a three-bedroom apartment, with a mean of $11.1 \mathrm{~s}$ and a standard deviation of $4.7 \mathrm{~s}$.

The corridor smoke control system is assumed to activate immediately upon smoke detection within the corridor, after the apartment door opens for occupant escape. This approach has been taken for simplification of the modelling, although in practice there may be a nominal ramp-up time following detection for the system to activate and reach maximum capacity (as noted in SCA guidance).

\subsection{Number of Simulation Iterations and Simulation Time}

For the probabilistic modelling, a total of 1000 iterations have been simulated. For each iteration, the simulation time has been capped at $1800 \mathrm{~s}$ (30 min). An appropriate number of iterations has been verified based on observations of convergence for the smoke clearance time, with a particular focus on the convergence of the mean and standard deviation. These values, as a function of the number of iterations, are presented in Fig. 6. From this, it appears that the mean smoke clearance time and the standard deviation have both effectively converged (remaining within $1 \%$ of the 'final' average value) after approximately 750 iterations, indicating that the adopted number of iterations is adequate for the outcome to be considered independent of the sample size. 


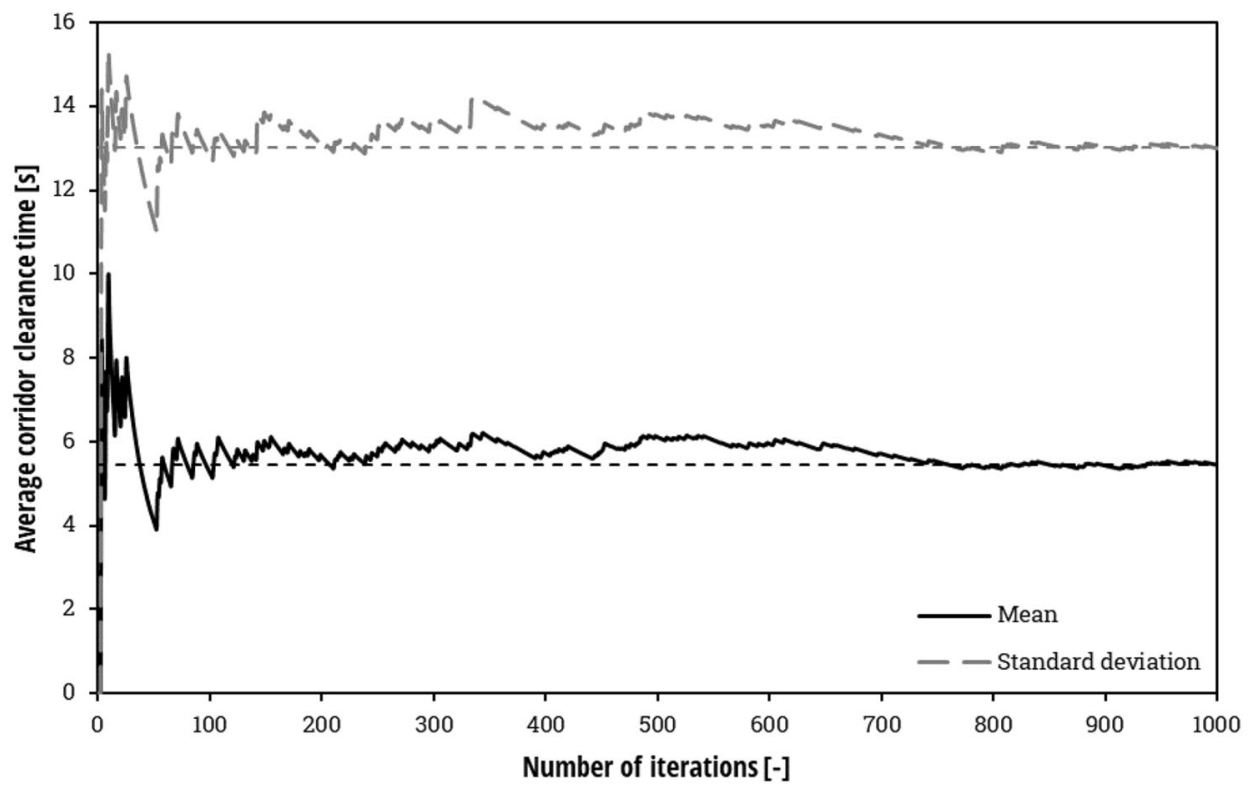

Figure 6. The mean and standard deviation for the estimated corridor clearance time with increasing iterations.

\section{A Summary of Study Limitations}

In undertaking probabilistic modelling to present what is intended to be a full range of potential outcomes, it must be acknowledged that this approach does not eliminate all uncertainty and a lesser degree of uncertainty will remain within the selected distribution functions, the adopted methodology, the interaction of input parameters, the model uncertainties, the ability of the model to reflect reality, etc. [28]. Several major limitations of the methodology are listed below, although there will be more that have not been mentioned for reasons of brevity. Limitations include:

- A certain degree of confidence is placed in B-RISK's capability to appropriately capture the fire and smoke phenomena under scrutiny, with reference to previous benchmarking studies. B-RISK is a relatively simple, two-zone model and does not achieve the fidelity of other fire and smoke modelling tools, such as computational fluid dynamics (CFD) based tools. However, a counter-argument to this is that simpler models can be adopted to maintain a 'consistent level of crudeness', where the level of detail in a process should be governed by the crudest part of that process [58] which, in this instance, includes many simplified input assumptions. In addition, high-fidelity tools might be considered less suited to extensive sensitivity studies due to the computational resources required, and may therefore require more detailed consideration of sampling methods to reduce the number of iterations [4]. 
- Certain distribution functions are derived from a limited amount of experimental data or information, such as the effective heat of combustion and radiative fraction. In addition, one of the distribution functions, the elevation of the fuel bed, has been arbitrarily defined and is not based on real data.

- The modelling applies historical data for sprinkler reliability. Although it is difficult to identify, it is expected that the data is largely derived from incidents for exposed pendent heads. It is therefore unlikely to capture complications associated with concealed heads, such as the potential for occupants to 'paint-over' or obstruct the concealer plate.

- Aside from incorporating sprinkler reliability parameters, the modelling otherwise assumes an as-built system reliability and performance for other fire safety systems, such as fire doors (and closers), compartmentation, and the smoke control system itself. Thus, any issues associated with an absence of expected performance, or from poor building maintenance, are not captured.

- Given the distribution functions are generally derived from past experiments or historical incident data, their veracity can always be brought into question, i.e., to what extent can these functions be considered representative of a range of real fire incidents occurring under present day conditions? For example, the applicability of the soot yield data for furniture fires, some of which dates as far back as the 1980s, could be questioned on whether it is truly representative of modern-day residential fuel loads.

- The modelling assumes that the interaction of input parameters is broadly independent. That is, the sampling of one distribution function is not influenced by the sampling of another. An example of this limitation is the relationship between the HRR and the soot yield, where typically flaming and well-ventilated fires with large HRRs might have lower soot yields $(\mathrm{kg} / \mathrm{kg})$ than underventilated fires with lower HRRs [38].

- The assumed low-level vent, incorporated into the modelling to sustain the HRR, has been specified independently of the window area of the apartment. This vent area could have an impact on the estimated conditions within the apartment, which could subsequently impact the smoke clearance time.

- The modelling applies a distribution function for pre-flashover soot yields, largely derived from experimental data for free-burn or well-ventilated conditions, without assessing the impact ventilation-controlled conditions could have on this parameter.

- The modelling does not consider the impact wind could have on the apartment of fire origin or the ventilation system. Depending on wind direction and speed, and resultant external pressures, this could either have a detrimental or beneficial impact on smoke movement within the building.

- The behavioural timeline, and the representation of occupants within the apartment, has been heavily simplified to focus solely on the time that the apartment door opens and closes during escape. As part of this, the interaction between the development of fire and smoke in the apartment, and the behaviour of occupants within the apartment, has not been represented. 


\section{Simulation Results}

Figure 7 presents the cumulative density functions (CDFs) for the corridor clearance time, which is the time for the corridor to return to tenable conditions (visibility above $10 \mathrm{~m}$ and temperature below $60^{\circ} \mathrm{C}$ ) at a height of $2 \mathrm{~m}$ from floor level. This time is measured from the point that the apartment door closes following escape. Two different CDFs are presented, as the sensitivity of the selected door open time distribution has been considered: a CDF assuming a one-bedroom apartment door open time, representative of the exemplar; and a CDF assuming a three-bedroom apartment door open time. From the CDFs it can be observed that in $83 \%$ (one-bedroom) and $79 \%$ (three-bedroom) of cases, the clearance time is shown to be zero, indicating that an insufficient quantity of smoke spreads from the apartment of fire origin into the corridor to result in untenable conditions within the corridor at any stage. After this point, the clearance time increases reaching a 100th percentile within $84 \mathrm{~s}$. Comparing these distributions to the deterministic simulations undertaken using the recommendations of SCA guidance for a $1 \mathrm{MW}$ design fire suggests that the SCA guidance approach results in greater than the 99th percentile (both one-bedroom and three-bedroom). For a $635 \mathrm{~kW}$ sprinkler-controlled design fire, the percentiles are approximately the 99th percentile for both the one-bedroom and three-bedroom CDF.

The CDF for the estimated maximum HRR in the apartment of fire origin is shown in Fig. 8. This figure indicates that the $1 \mathrm{MW}$ design fire represents a 96th

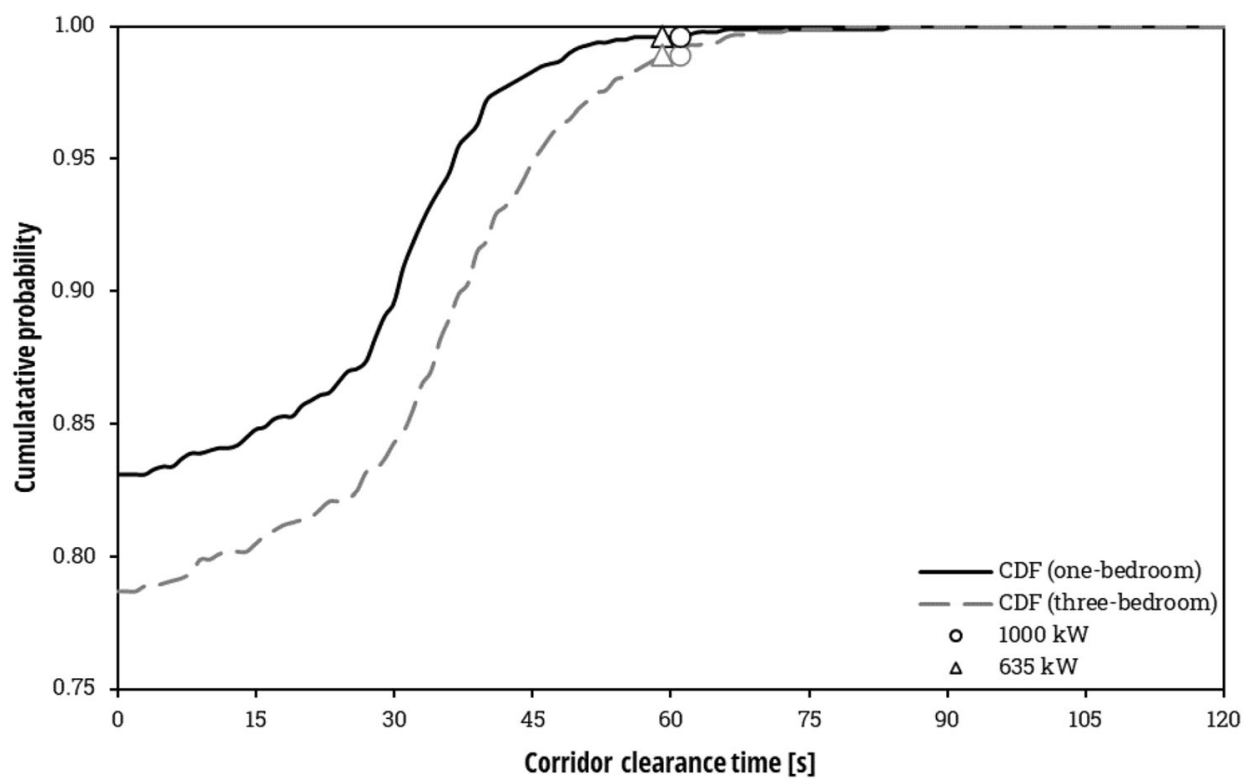

Figure 7. CDFs for corridor clearance time for two different door open time distribution assumptions. 


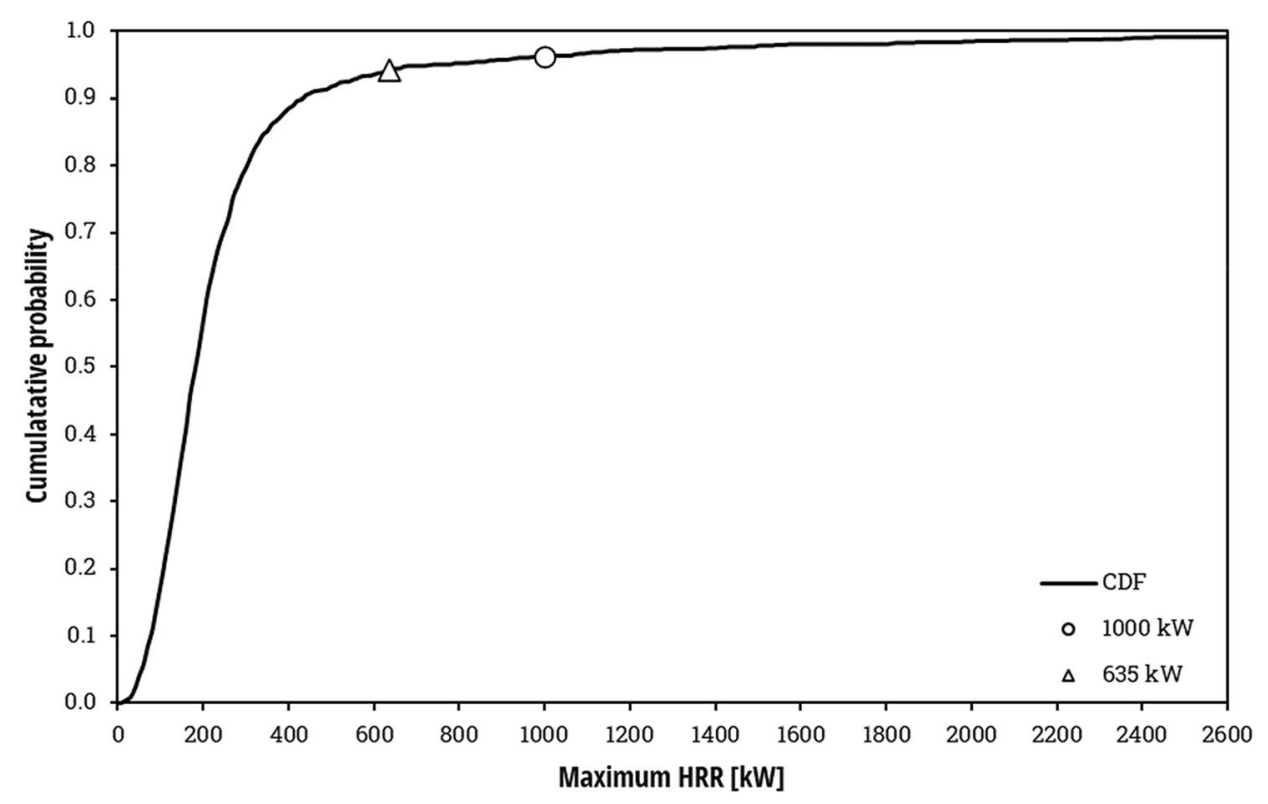

\section{Figure 8. CDF for the maximum HRR.}

percentile, with the $635 \mathrm{~kW}$ sprinkler-controlled fire equating to the 94th percentile.

To assess the relative sensitivity of the individual parameters, a series of simulations have been run where each distribution function has been individually considered from a 1st percentile and 99th percentile. When the individual parameter is being assessed for either the 1st or 99th percentile, all other parameters are set to the recommended parameters provided in the SCA guidance (excluding any consideration of window failure). The sensitivity of the parameters is presented using a tornado plot, as shown in Fig. 9. The plot ranks the parameters from the widest (top) to the narrowest (bottom) range based on their impact on the estimated corridor clearance time, i.e., the top represents the 'most sensitive' parameter on the corridor clearance time while the bottom represents the 'least sensitive'. Colour coding has been used to differentiate fire (red), sprinkler (blue) and behavioural (grey) parameters.

The results presented in Fig. 9 highlight the importance of behavioural assumptions within a common corridor model, with the pre-evacuation time (i.e., the time the apartment door is first opened) and the door open time representing the 1st and 3rd most sensitive parameter, respectively. The pre-evacuation time is shown to produce a range of $58 \mathrm{~s}$ in the corridor clearance time, and the door open time a range of $42 \mathrm{~s}$. After this, the most sensitive parameters are fire-related parameters, including the elevation of the fuel bed ( $2 \mathrm{nd}, 57 \mathrm{~s}$ ), the soot yield ( 4 th, $41 \mathrm{~s}$ ), the fire growth rate $(5 \mathrm{th}, 40 \mathrm{~s})$, and the effective heat of combustion (6th, $14 \mathrm{~s})$. However, it must be reiterated that the distribution function for the elevation of the fuel bed has been arbitrarily defined. Less impactful fire parameters are the 


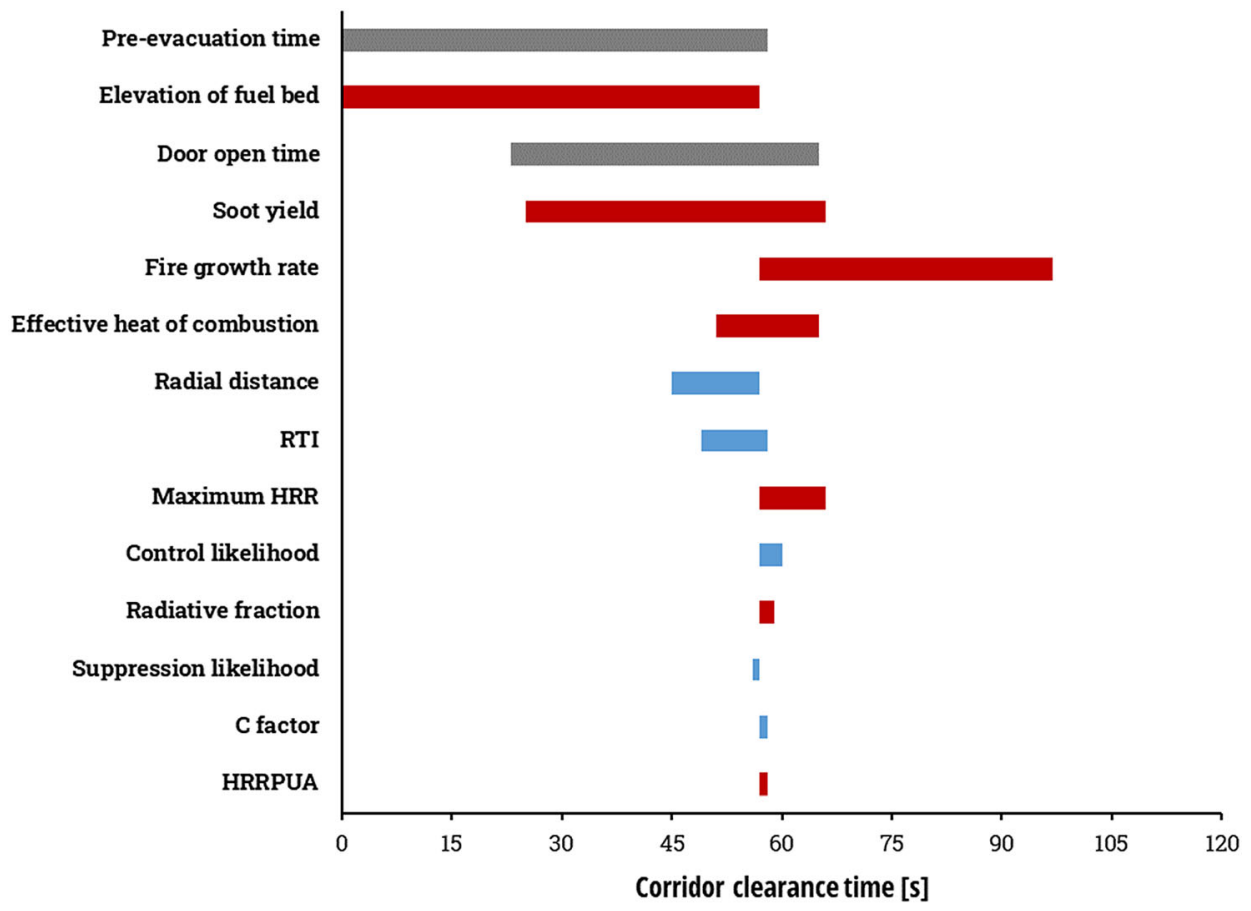

\section{Figure 9. Tornado plot of the impact of parameter sensitivity on estimated corridor clearance time.}

maximum HRR ( $=8$ th, $9 \mathrm{~s}$ ), radiative fraction (11th, $2 \mathrm{~s}$ ), and the HRRPUA $(=12$ th, $1 \mathrm{~s})$. It is important to note that the maximum HRR's limited impact demonstrated in the tornado plot is in part due to the fixed nature of the behavioural parameters (pre-evacuation time and door open time) along with the fixed growth rate. Even when the fire can grow larger (e.g., larger than $1 \mathrm{MW}$ ), this increased HRR does not impact the quantity of smoke entering the corridor because occupant escape has often already occurred before this point in time, whereas a change in the fire growth rate will directly impact the HRR at the time that the apartment door opens.

The tornado plot appears to indicate that, collectively, the assumptions around sprinkler performance are less sensitive, with the radial distance (7th, $12 \mathrm{~s}$ ) and RTI ( $=8$ th, 9 s) having the greatest impact of these parameters. The control likelihood (10th, $3 \mathrm{~s})$, suppression likelihood (= 12th, $1 \mathrm{~s})$, and $\mathrm{C}$ factor $(=12 \mathrm{th}, 1 \mathrm{~s})$ are shown to be less impactful.

By assuming fixed values for all other parameters when varying a single parameter, the approach to producing the tornado plot comes with limitations in how it assesses sensitivity. It is possible that certain parameters can become more or less sensitive in relation to other parameters when those parameters are also changed. For example, as mentioned above, the sensitivity of the maximum HRR is shown to be less when the behavioural parameters and fire growth rate are fixed in a way 
that the maximum HRR cannot be met before occupants make their escape. Similarly, the soot yield may be expected to have less sensitivity for higher assumed values of effective heat of combustion, due to the relative reduction on the estimated production of soot. Given these limitations, although a useful exercise, the outcome of the tornado plot should be observed with a degree of caution.

\section{Discussion and Conclusions}

Multi-apartment residential buildings in the UK typically incorporate a smoke control system within the common corridor. Under certain circumstances, this system can be used to support the design of buildings where extended corridor travel distances are observed, by facilitating the smoke clearance of the corridor should it ever become compromised. When proposing a smoke control system to support extended travel distances, a fire and smoke modelling assessment is usually undertaken, often applying the recommendations of SCA guidance. However, it is not always clear how the recommendations and assumptions of this modelling guidance have been derived, nor is it clear the severity of fire scenario they can collectively be considered to represent on a range of possible outcomes. Therefore, probabilistic zone modelling, using MCS in B-RISK and distribution functions from past literature, has been undertaken for a single exemplar residential building arrangement. The purpose of this modelling is to examine where the deterministic assumptions of SCA guidance sit on a distribution of outputs, with a focus on the time for the corridor to return to tenable conditions after becoming compromised with smoke (i.e., the corridor clearance time). The exemplar considers a single ventilation arrangement with a fixed volumetric flow rate of $3 \mathrm{~m}^{3} / \mathrm{s}$, considered to be broadly representative of a system design which might be observed in practice. It is acknowledged that the selected ventilation provisions will have a substantial effect on the observed corridor clearance time. The sensitivity of this has not been assessed herein, instead focussing on inputs which are intended to represent the potential range of fire and evacuation scenarios.

The probabilistic modelling indicates that the application of SCA guidance assumptions produces a scenario severity which is equal to or greater than the 99th percentile of possible outcomes for the estimated corridor clearance time, depending on the selected distribution function for the door open time. From this, it may be postulated that the recommendations contained within the SCA guidance are representative of an upper bound, and its application would not result in an inadequate level of demonstrated fire safety performance. Hopkin et al. [28] previously suggested, when considering safety factors, that "Some engineers may contend that this is a reasonable approach to take as, particularly in fire engineering design, 'more conservative' is often be equated with 'better'." However, the point is made that the intent in the fire engineering design of buildings is not one of achieving absolute safety and zero residual risk, but instead to achieve an 'adequate level' of safety. Hopkin et al. refer to the 'as low as is reasonably practicable' (ALARP) concept, as embedded in health and safety law [59], and the ethical obligations of engineers to maximise societal welfare under the constraint of finite 
resources. It is this concept that allows for failure likelihoods to be adopted in design, such as structural fire resistance ratings provided in BS 9999:2017 [60] (for given ventilated conditions). These ratings are calibrated on the basis of a $20 \%$ failure likelihood for an $18 \mathrm{~m}$ tall office building exemplar [61], in the event of a structurally significant fire. There may therefore be a reasonable argument for revisiting SCA guidance input parameter assumptions in future to address acceptable failure likelihoods in the context of failure consequence, rather than the current approach where it appears an upper bound is uniformly considered for all building situations. However, it is important to acknowledge that the modelling methodology is based on common fire safety design assumptions and comes with a number of limitations in how it considers certain factors, such as only assessing the as-built system reliability (with the exception of sprinkler performance) and not capturing the impact of potential failures in maintenance. In defining any acceptable failure likelihoods in future, the potential for the in-use compromise of as-built system reliability would need to be carefully investigated.

In addition to the probabilistic modelling, the sensitivity of individual input parameters has been observed (by simulating the 1st and 99th percentile), and these parameters are ranked based on their demonstrated influence on the estimated corridor smoke clearance time. The sensitivity analyses highlight the importance of behavioural assumptions around the pre-evacuation time (producing a $58 \mathrm{~s}$ range in the clearance time) and door open time (42 s), and the significance of fire parameters including the elevation of the fuel bed (57 s), soot yield (41 s), and fire growth rate $(40 \mathrm{~s})$. Sprinkler parameters are shown to have a lesser impact on the corridor clearance time, with the most sensitive parameter being the radial distance $(12 \mathrm{~s})$. Consequently, if practitioners were to assess the sensitivity of certain parameters on the demonstrated smoke control system performance in relation to SCA guidance assumptions, then it may be pertinent to consider behavioural assumptions (pre-evacuation time and door open time), elevation of the fuel bed, fire growth rate, and soot yield ahead of others, although caution should be exercised when considering the potential interaction between parameters. The work also indicates that further investigation of an appropriate distribution function for the elevation of the fuel bed is likely warranted.

\section{Open Access}

This article is licensed under a Creative Commons Attribution 4.0 International License, which permits use, sharing, adaptation, distribution and reproduction in any medium or format, as long as you give appropriate credit to the original author(s) and the source, provide a link to the Creative Commons licence, and indicate if changes were made. The images or other third party material in this article are included in the article's Creative Commons licence, unless indicated otherwise in a credit line to the material. If material is not included in the article's Creative Commons licence and your intended use is not permitted by statutory regulation or exceeds the permitted use, you will need to obtain permission 
directly from the copyright holder. To view a copy of this licence, visit http://creat ivecommons.org/licenses/by/4.0/.

\section{Acknowledgement}

The authors would like to thank Yokelee Tan for bringing the notation errors in Figs. 6 and 7 to our attention.

\section{References}

1. HM Government (2020) The building regulations 2010, approved document B (Fire Safety) volume 1 (2019 edition, as amended May 2020)

2. BSI (2015) BS 9991:2015 Fire safety in the design, management and use of residential buildings. Code of practice. BSI, London

3. Scottish Government (2019) Building standards technical handbook 2019: domestic

4. Hopkin D, Hopkin C, Spearpoint M, Ralph B, Van Coile R (2019) 'Scoping study on the significance of mesh resolution vs. scenario uncertainty in CFD modelling of residential smoke control systems', presented at the Interflam, Royal Holloway

5. Hopkin C, Spearpoint M, Hopkin D, Wang Y (2021) Estimating door open time distributions for occupants escaping from apartments. Int J High-Rise Build 10(1):73-83. https://doi.org/10.21022/IJHRB.2021.10.1.73

6. Smoke Control Association (SCA) (2020) Guidance on smoke control to common escape routes in apartment buildings (flats and maisonettes), revision 3.1. Federation of Environmental Trade Associations

7. SCA (2022) Smoke control association. https://www.smokecontrol.org.uk/home. Accessed 26 Jan 2022

8. Hopkin C, Spearpoint M, Henderson A, Hopkin D (2017) Smoke control association guide: benchmarking firefighting tenability criteria against accepted designs. Int Fire Profess J 22:51-54

9. Smoke Control Association (SCA) (2021) Guidance on CFD analysis for smoke control design in buildings, edition 1. Federation of Environmental Trade Associations

10. Wade C, Baker G, Frank K, Harrison R, Spearpoint M (2016) B-RISK 2016 user guide and technical manual. Building Research Association of New Zealand, SR364

11. Hopkin C, Spearpoint M, Wang Y, Hopkin D (2019) Design fire characteristics for probabilistic assessments of dwellings in England. Fire Technol . https://doi.org/ 10.1007/s10694-019-00925-6

12. Robbins A, Wade C (2008) Soot yield values for modelling purposes - residential occupancies. Building Research Association of New Zealand, SR185

13. Sundström B (1995) Fire safety of upholstered furniture - the final report on the CBUF research programme. European Commission and Measurements and Testing Report EUR 16477 EN

14. Babrauskas V, Krasny J (1985) Fire behavior of upholstered furniture. National Bureau of Standards, Gaithersburg, MD, NBS Monograph 173

15. Gann R, Averill J, Johnsson E, Nyden M, Peacock R (2003) Smoke components yields from room-scale fire tests. National Institute of Standards and Technology, Gaithersburg, MD, NIST Technical Note 1453 
16. Fang FB, Breese JN (1980) Fire development in residential basement rooms. National Bureau of Standards, Gaithersburg, MD, NBS IR 80-2120. https://doi.org/10.6028/NB S.IR.80-2120

17. BSI (2019) PD 7974-7:2019 Application of fire safety engineering principles to the design of buildings. Probabilistic risk assessment. BSI, London

18. Ikehata Y, Yamaguchi J, Deguchi Y, Tanaka T (2015) Statistical analysis on the reliability of sprinkler systems: study on a risk-based evacuation safety design method. Fire Sci Technol 2017:331-339

19. Hopkin C, Spearpoint M (2020) Numerical simulations of concealed residential sprinkler head activation time in a standard thermal response room test. Build Serv Eng Res Technol . https://doi.org/10.1177/0143624420953302

20. Lovreglio R, Kuligowski E, Gwynne S, Boyce K (2019) A pre-evacuation database for use in egress simulations. Fire Saf $\mathrm{J}$ 105:107-128. https://doi.org/10.1016/j.firesaf.2018.12.009

21. Lovreglio R, Kuligowski E, Gwynne S, Boyce K (2019) Corrigendum to "A pre-evacuation database for use in egress simulations" [Fire Safety J. 105, 2019, 107-128]. Fire Saf J 108:102829. https://doi.org/10.1016/j.firesaf.2019.102829

22. Hopkin C, Spearpoint M, Hopkin D, Wang Y (2020) Fire safety design of open plan apartments in England. Arch Eng Des Manage 1-20. https://doi.org/10.1080/17452007. 2020.1719812

23. Hopkin C, Spearpoint M, Hopkin D, Wang Y (2019) Residential occupant density distributions derived from English Housing Survey data. Fire Saf J 104:147-158. https:// doi.org/10.1016/j.firesaf.2019.01.010

24. BSI (2020a) BS 5839-6:2019 + A1:2020 Fire detection and fire alarm systems for buildings. Code of practice for the design, installation, commissioning and maintenance of fire detection and fire alarm systems in domestic premises. BSI, London

25. BSI (2021) BS 9251:2021 Fire sprinkler systems for domestic and residential occupancies. Code of practice. BSI, London

26. BSI (2020b) BS EN 12259-14:2020 Fixed firefighting systems. Components for sprinkler and water spray systems. Sprinklers for residential applications. BSI, London

27. Wade C (2013) Room size limits when using a fire zone model for smoke-filling calculations. BRANZ Research Institute of New Zealand, Technical Recommendation TR17

28. Hopkin C, Hopkin D, Spearpoint M (2021) Safety factors: can they be inherently captured in modelling assumptions? A short scoping study. Int Fire Profess J 37

29. Wade C (2013) B-RISK software benchmarking examples. Building Research Association of New Zealand, Study Report SR292

30. Harrison R, Wade C, Spearpoint M (2014) Predicting spill plumes with the fire risk zone model B-RISK. Fire Technol 50(2):205-231. https://doi.org/10.1007/s10694-0130364-3

31. Davis W (1999) The zone fire model jet: a model for the prediction of detector activation and gas temperature in the presence of a smoke layer. National Institute of Standards and Technology, Gaithersburg, MD, NISTIR 6324

32. Wade C, Spearpoint M, Bittern A, Tsai K (2007) Assessing the sprinkler activation predictive capability of the BRANZFIRE fire model. Fire Technol 43(3):175-193. https:// doi.org/10.1007/s10694-007-0009-5

33. Hopkin C, Spearpoint M (2019) Evaluation of sprinkler actuation times in FDS and BRISK. Int Fire Profess J 28:22-27

34. Barbu A, Zhu S-C (2020) Introduction to Monte Carlo methods. In: Barbu A, Zhu S-C (eds) Monte Carlo methods. Springer, Singapore, pp 1-17. https://doi.org/10.1007/978-9 81-13-2971-5_1 
35. Lovreglio R, Spearpoint M, Girault M (2019) The impact of sampling methods on evacuation model convergence and egress time. Reliab Eng Syst Saf 185:24-34. https:// doi.org/10.1016/j.ress.2018.12.015

36. BSI (2019) PD 7974-6:2019 Application of fire safety engineering principles to the design of buildings. Human factors. Life safety strategies. Occupant evacuation, behaviour and condition (Sub-system 6). BSI, London

37. Babrauskas V, Lawson R, Walton W, Twilley W (1982) Upholstered furniture heat release rates measured with a furniture calorimeter. National Bureau of Standards, Washington, DC, NBSIR 82-2604

38. BSI (2019) 'PD 7974-1:2019 Application of fire safety engineering principles to the design of buildings. Initiation and development of fire within the enclosure of origin (Sub-system 1). BSI, London

39. Hopkin C, Spearpoint M, Hopkin D (2019) A review of design values adopted for heat release rate per unit area. Fire Technol 55(5):1599-1618. https://doi.org/10.1007/s10694019-00834-8

40. Smoke Control Association (SCA) (2012) Guidance on smoke control to common escape routes in apartment buildings (flats and maisonettes), revision 1. Federation of Environmental Trade Associations

41. Smoke Control Association (SCA) (2015) Guidance on smoke control to common escape routes in apartment buildings (flats and maisonettes), revision 2. Federation of Environmental Trade Associations

42. Morgan H, Ghosh B, Garrad G, Pamlitschka R, De Smedt, J-C, Schoonbaert L (1999) BR 368, design methodologies for smoke and heat exhaust ventilation. Building Research Establishment (BRE) Press

43. McGrattan K, Hostikka S, McDermott R, Floyd J, Vanella M (2019) Fire dynamics simulator user's guide. National Institute of Standards and Technology, Gaithersburg, MD, NIST SP 1019. https://doi.org/10.6028/NIST.SP.1019

44. Ministry of Business, Innovation \& Employment (2013) C/VM2, verification method: framework for fire safety design, for New Zealand Building Code clauses C1-C6 protection from fire. New Zealand Government, Amendment 3

45. BSI (2011) BS 9252:2011 Components for residential sprinkler systems. Specification and test methods for residential sprinklers. BSI, London

46. Annable K (2006) DCLG final research report, effectiveness of sprinklers in residential premises - an evaluation of concealed and recessed pattern sprinkler products, Section 5: thermal sensitivity. Building Research Establishment [Online]. Available: http://www.br e.co.uk/filelibrary/pdf/rpts/partb/218113_final_report_section_1_summary_report.pdf

47. Yu K (2007) Investigation of recessed and concealed sprinklers activation in wind tunnel plunge test and in BRANZFIRE computer model. Master's thesis, University of Canterbury. Accessed 17 Sep 2019. [Online]. Available: https://ir.canterbury.ac.nz/handl e/10092/1184

48. Fraser-Mitchell J, Williams C (2012) Cost benefit analysis of residential sprinklers-final report. BRE Global, Project Report Number 264227 rev1.1

49. BSI (2014) BS 9251:2014 Fire sprinkler systems for domestic and residential occupancies. Code of practice. BSI, London

50. Bukowski RW, Budnick EK, Schemel CF (1999) Estimates of the operational reliability of fire protection systems. Boston

51. Hopkin D, Lennon T, El-Rimawi J, Silberschmidt V (2012) A numerical study of gypsum plasterboard behaviour under standard and natural fire conditions. Fire Mater 36(2):107-126. https://doi.org/10.1002/fam.1092 
52. BSI (2005) BS EN 1992-1-2:2004+ A1:2019 Eurocode 2. Design of concrete structures. General rules. Structural fire design. BSI, London

53. HM Government (2013) The building regulations 2010, approved document F (ventilation) (2010 edn, incorporating 2010 and 2013 amendments)

54. Parry R, Wade C, Spearpoint M (2003) Implementing a glass fracture module in the BRANZFIRE zone model. J Fire Prot Eng 13(3):157-183. https://doi.org/10.1177/ 1042391503033366

55. Galea ER, Deere SJ, Hopkin CG, Xie H (2017) Evacuation response behaviour of occupants in a large theatre during a live performance. Fire Mater 41(5):467-492. https://doi.org/10.1002/fam.2424

56. Gwynne S, Boyce K (2016) Engineering data. In: SFPE handbook of fire protection engineering, 5th edn. Springer, pp 2429-2551

57. Frank KM (2013) Fire safety system effectiveness for a risk-informed design tool. $\mathrm{PhD}$ Thesis, University of Canterbury [Online]. https://ir.canterbury.ac.nz/handle/10092/8495 . Accessed 26 Feb 2020

58. Elms DG (1992) Consistent crudeness in system construction. In: Topping BHV (ed) Optimization and artificial intelligence in civil and structural engineering: volume I: optimization in civil and structural engineering. Springer Netherlands, Dordrecht, pp 71-85. https://doi.org/10.1007/978-94-017-2490-6_6

59. legislation.gov.uk (2020) Health and Safety at Work etc. Act 1974. UK Legislation. htt ps://www.legislation.gov.uk/ukpga/1974/37/contents. Accessed 5 Nov 2020

60. BSI (2017) BS 9999:2017 Fire safety in the design, management and use of buildings. Code of practice. BSI, London

61. Kirby B, Newman G, Butterworth N, Pagan J, English C (2004) A new approach to specifying fire resistance periods. Struct Eng J Inst Struct Eng 19:34-37

Publisher's Note Springer Nature remains neutral with regard to jurisdictional claims in published maps and institutional affiliations. 